Contents list available at IJRED website

Int. Journal of Renewable Energy Development (IJRED)

\title{
Premixed Combustion of Coconut Oil in a Hele-Shaw Cell
}

\author{
${ }^{1}$ Hadi Saroso, ${ }^{2}$ I.N.G. Wardana, ${ }^{3}$ Rudy Soenoko, ${ }^{4}$ Nurkholis Hamidi \\ ${ }^{1}$ Department of Mechanical Engineering, State Polytechnic of Malang \\ 1,2,3,4Deparment of Mechanical Engineering, Faculty of Engineering, Brawijaya University.
}

\begin{abstract}
Coconut oil combustion characteristic is observed experimentally by evaporating oil in the boiler then mix it with air before being burned at various equivalence ratios in the Hele-shaw cell. The result shows that, coconut oil tends to break into glycerol and fatty acid due to hydrolysis reaction producing the flame propagation, where the fatty acid flame propagates first then glycerol flame. Micro-explosion occurs when moisture from fatty acid combustion is absorbed by glycerol and higher heating due to higher flame speed produces more micro-explosion.
\end{abstract}

Keywords: Premixed combustion, coconut oil, glycerol, fatty acid, micro-explosion.

Article History: Received May 15, 2014; Received in revised form Sept 12, 2014; Accepted Sept 20, 2014 ; Available online

How to Cite This Article: Saroso,H., Wardana,I.N.G., Soenoko, R., Hamidi. N., (2014) Premixed combustion of coconut oil in a hele-shaw cell. Int. Journal of Renewable Energy Development, 3(3), 155-160.

http://dx.doi.org/10.14710/ijred.3.3.155-160

\section{Introduction}

The motivation for this investigation comes from the flame propagation behavior related to micro-explosion of multi-component oil, where the fatty acid flame propagates first then glycerol flame and water vapor is trapped between fatty acid and glycerol. Regarding to combustion of multi-component oil, Cornet et al. (1955) and Turner and Siegmund (1973) state that the quality of the vegetable oil fuel is determined by the nature of physical and chemical properties such as volatility, diffusivity, and reactivity. The coconut oil combustion is very attractive for industrial application and diesel engines. However, the direct coconut oil combustion has many problems related to the viscosity which is about ten times as high as biodiesel (Muniyappa et al. 1996). High viscosity of vegetable oil, particularly coconut oil contains fatty acid and glycerol. Agarwal and Agrawal (2007) stated that the initial heating is one way to produce jatropha oil combustion process in diesel engine. The findings of the study shows that coconut oil can be heated directly used to replace diesel fuel and it does not require major engine modification (Sahoo and Das, 2009). It seems that in the future, the coconut oil combustion would be an alternative. Another study was describing the efficiency of diesel engine by using vegetable oil directly (Özkan et al. 2005). Effect of high temperature on multiple component fuel combustion has been studied by Xu G (2003). An analytical study has been conducted to identify the combustion characteristics of propanol blended with glycerol at a reduced buoyancy (Dee et al. 2004). The difference between the boiling point of propanol and glycerol causes micro-explosions. The micro-explosion preserves to occur in the coconut oil because fatty acid and glycerol in coconut oil has different boiling points.

At high Lewis number $\overline{\bar{T}}_{\overline{1}}$ the smaller diffusion coefficient of mass reduce the amount of water absorbed, and at low number Lewis, the greater mass diffusion coefficient increase rate of water loss to the atmosphere, reducing the water concentration in flame. Consequently, the absorption level can maximize the moderate Lewis number (Zhang et al. 1998).

It has been identified in several studies, one conducted by Wardana (2010) who examined the combustion characteristic of the jatropha oil droplet at various temperatures, that jatropha oil droplet undergo two-stage combustion. The emerging of microexplosion occurs shortly before the burning of the second step and it happens more often, because the oil

*Corresponding author:

E-mail : s.hadisaroso@yahoo.com (Hadi Saroso) 
temperature increases. Glycerol has a higher boiling point than the fatty acid that causes problems in the initial heating, and it also absorbs water from fatty acid combustion produces micro-explosion.

Kang et al. (2006) examined the effect of heat loss of laminar flame premixed combustion momentum in a narrow slit. It was found that two factors play a complex role in determining the shape of the instability entire cell. To make the efficient process in very stable premixed combustion, micro-explosion plays an important role in combustion speed.

This article is presented for a study focused on the identification of the micro-explosion in coconut oil premixed combustion. Water vapor is a very interesting thing that affects mass transfer and other transport. The temperature difference triggered by the instability of the flame propagation can also trigger a chemical reaction drastically. Several studies have been conducted to understand the micro-explosion in flame propagation (Wang et al. 2005; Nam and Alvarado, 2012). Few studies have also been done on premixed combustion of multi-component fuel (Abdul Wahid et al. (2009). However, very little can be found regarding the micro-explosions on coconut oil premixed combustion in Hele-shaw cell. Therefore, this study focuses on identifying the characteristic of coconut oil premixed combustion in Hele-shaw cell.

\section{Experiments}

\subsection{Experimental apparatus and test procedure}

This research was conducted by using a set of experimental apparatus as shown in Figure 1. Combustion chamber was constructed by acrylic glass and steel plates with dimensions of $500 \times 200 \times 10 \mathrm{~mm}$ with igniter on the top and on the bottom. Overflow tube is used to collect water from the combustion chamber. Boiler is used to evaporate the coconut oil. Temperature controller is used to control the oil heater. The air from the compressor with coconut oil vapor from the boiler gives equivalent ratio $(\Phi)=1.35 ; 1.23$; $1.15 ; 1.05 ; 1.006 ; 0.95 ; 0.88$. High-speed CCD camera is used to record the shape of the flame propagation in the combustion chamber.

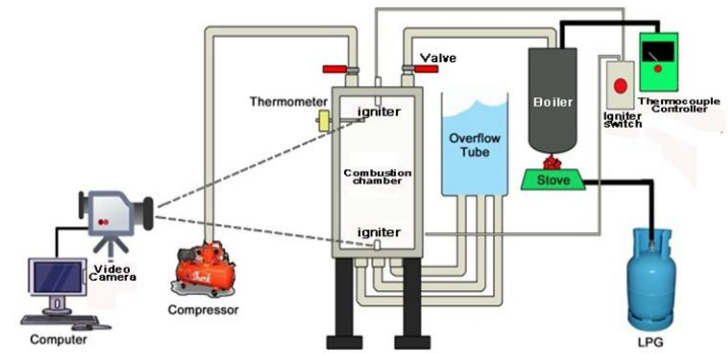

Fig. 1. Schematic of the experimental setup.

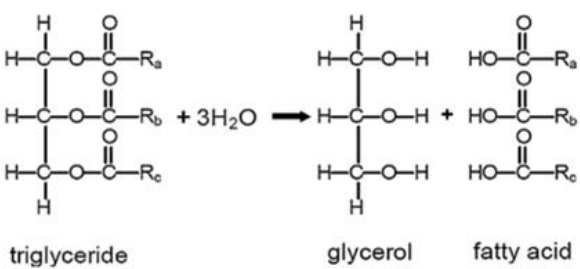

Fig.2. Hydrolisis Reaction of Triglyceride

Tabel 1 Fatty Acid Composition of Coconut Oil Vapor $\left( \pm 250^{\circ} \mathrm{C}\right.$ )

\begin{tabular}{|c|c|c|c|}
\hline Fatty Acid & $\begin{array}{l}\text { No.carbon::No. } \\
\text { double bond }\end{array}$ & Formula & $\begin{array}{c}\text { Composition } \\
\text { (\%) }\end{array}$ \\
\hline Lauryc Acid & $12: 0$ & $\mathrm{C}_{12} \mathrm{H}_{24} \mathrm{O}_{2}$ & 40.35 \\
\hline Myristic Acid & $14: 0$ & $\mathrm{C}_{14} \mathrm{H}_{28} \mathrm{O}_{2}$ & 11.45 \\
\hline Caprylic Acid & $8: 0$ & $\mathrm{C}_{8} \mathrm{H}_{16} \mathrm{O}_{2}$ & 18.13 \\
\hline Capric Acid & $10: 0$ & $\mathrm{C}_{10} \mathrm{H}_{20} \mathrm{O}_{2}$ & 14.63 \\
\hline
\end{tabular}

Recordings from the video camera was transferred to the Compact Disc (CD) in an AVI file. Then, using the Pinnacle software, moving images was extracted into a series of static images arranged chronologically from the beginning of fire until the flame reaches the end wall. Each composition of the mixture between air and fuel gives different patterns of flame image illustrated in Figure 3. The shape of the flame depicts the flame propagation. By using the software Adobe Photoshop CS3 the flame propagation distance and volumes of gas that burned between various flame propagations in each frame was estimated as in Figure 4, 5 and 6. Combustion instability behavior was analyzed based on the flame geometry.

\subsection{Coconut oil chemical structure and properties.}

Coconut oil has a common molecular structure as other vegetable oils called triglyceride as shown in Fig.2. The molecular structure contains four ester functional groups. Fig. 2 shows that hydrolysis reaction of triglyceride produces glycerol and fatty acids, which are carboxylic acids derived from coconut oils. In the fatty acids, $\mathrm{Ra}, \mathrm{Rb}$, and $\mathrm{Rc}$, represent groups of carbon and hydrogen atoms in which the carbon atoms are attached to each other in an unbranched chain. Fatty acid composition was determined using gas chromatography (GC). Mainly fatty acids found in coconut oil are lauric, myristic, caprylic and capric acid with composition as presented in Table 1.

\section{Results and discussion}

Figure 3 shows a picture of the flame propagating downward. The period of time between two frames is 0.034 seconds. Fatty acid flame propagates first then that of glycerol. Fatty acid combustion reaction produced water vapor, which is absorbed by glycerol producing micro-explosion. Flame propagation is the fastest at $\Phi=1.006$. At very rich mixture $(\Phi=1.35$ and 1.23) the greater fuel thermal conductivity make the 
flame thicker and slower reaction rate so that the color of former flame front is gray and the later flame is orange.

At a rich mixture $(\Phi=1.15,1.05$ and 1.006$)$ the smaller the fuel thermal conductivity make flame getting thinner with faster reaction rate, so that the color of former flame is blue and white and the color of alter flame is dark red. At poor mixture ( $\Phi=0.95$ and 0.88) the longer the fatty acid carbon chain, the more air is needed and the higher the evaporation temperature. It shows that glycerol needs a lot of air to burn so that the former flame is dark purple and the later flame is dark gray.

a). $\Phi=1.35$

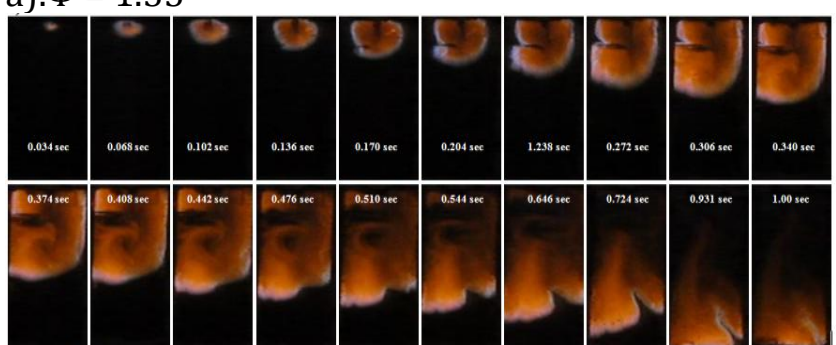

b). $\Phi=1.23$

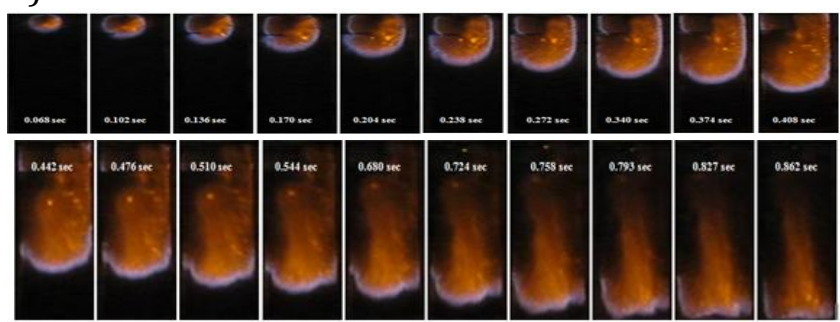

c). $\Phi=1.15$

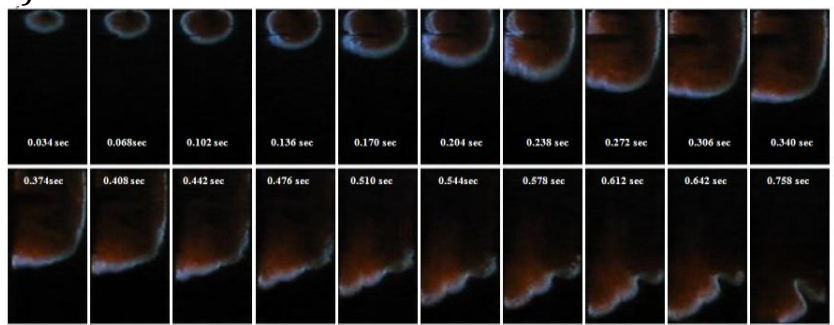

d). $\Phi=1.05$

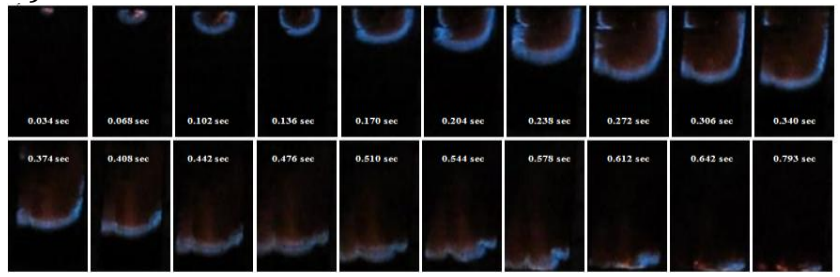

e). $\Phi=1.006$

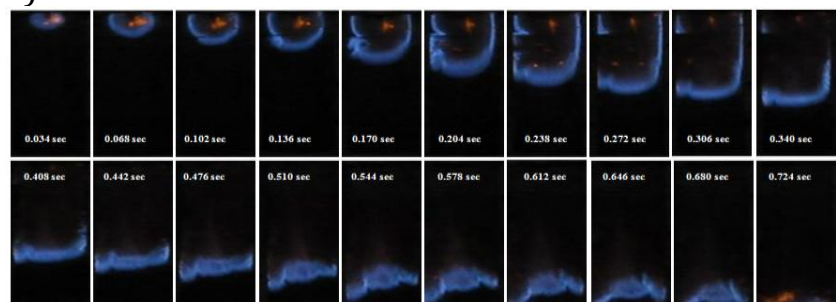

f). $\Phi=0.95$

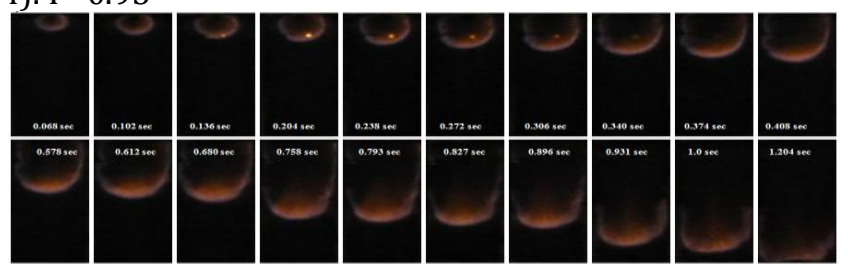

g). $\Phi=0.88$

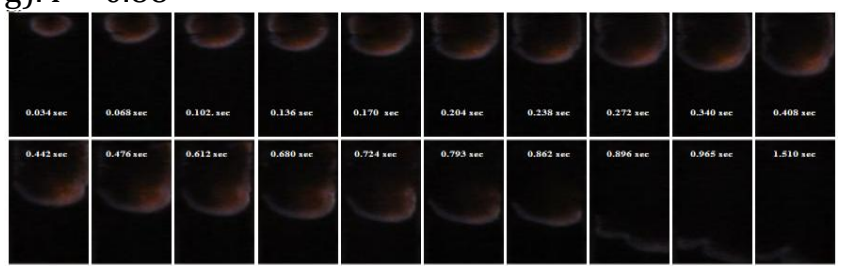

Figure 3 Flame propagation ignited from the top.

Figure 4 shows a picture of the flame propagation ignited from the bottom. Flame behavior almost the same with that in Figure 3. Fatty acid flame propagates first followed by glycerol flame. However, in figure $3 \mathrm{~b}$ since fatty acid flame propagates upward, the products of reaction, $\mathrm{CO}_{2}$ and $\mathrm{H}_{2} \mathrm{O}$ is below the flame. The $\mathrm{CO}_{2}$ gas which is lighter than fatty acids tends to enter the reaction zone which inhibits the flame propagation. Because glycerol absorbs $\mathrm{H}_{2} \mathrm{O}$, then it becomes heavier than fatty acid causing fatty acid flame is on the top and glycerol flame is below. The water that is absorbed by glycerol produces micro-explosion. The fastest flame propagation is at $\Phi=1.006$.

a). $\Phi=1.35$

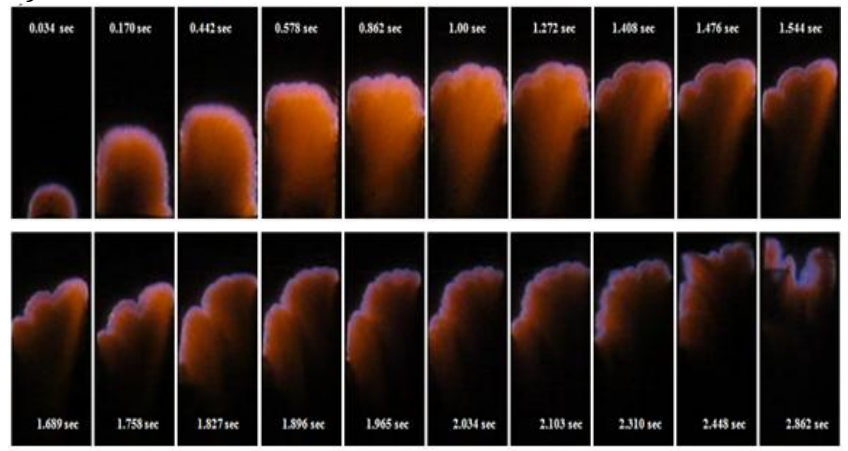

b). $\Phi=1.23$

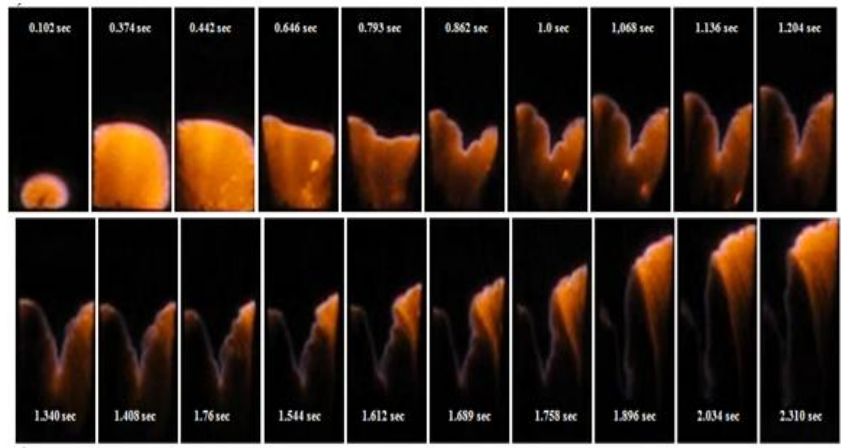


c). $\Phi=1.15$

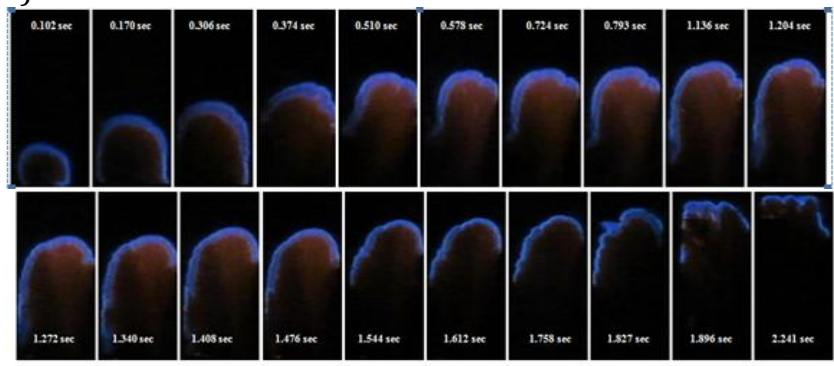

d). $\Phi=1.05$

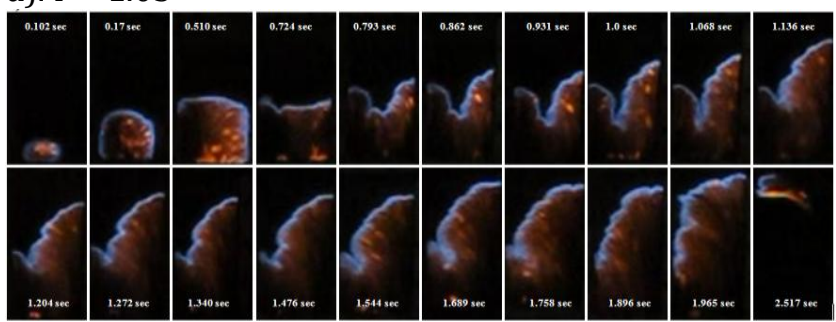

e). $\Phi=1.006$

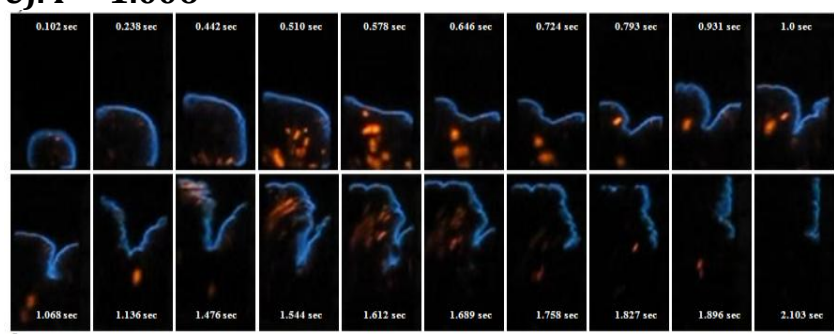

f). $\Phi=0.95$

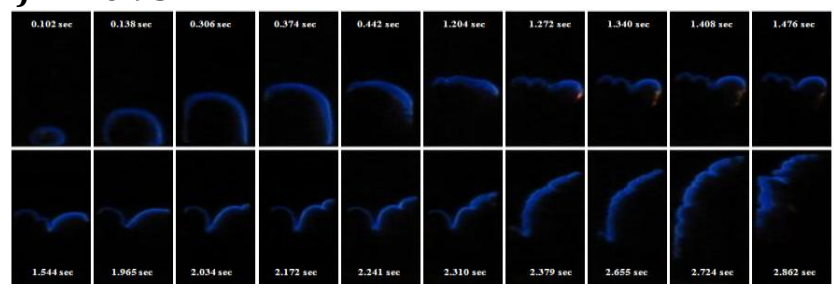

g). $\Phi=0.88$

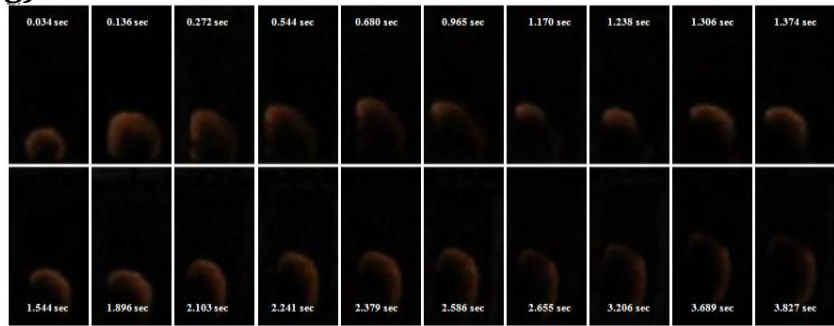

Figure 4 Flame propagation ignited from the bottom

Figure 5a shows the average distance of the flame with time at various $\Phi$ ignited from the top. At $\Phi=$ 1.006 the slope of the curve is the largest which shows that the flame propagation is the fastest. Consequently, less chance for glycerol to absorb water so the microexplosion is weak as shown in Figure 3.

Figure $5 b$ shows the average flame distance with time at various $\Phi$ ignited from the bottom. The slope of the curve is larger at $\Phi=1.006$. The flame distance delays in 0.442 seconds to 1.896 seconds.

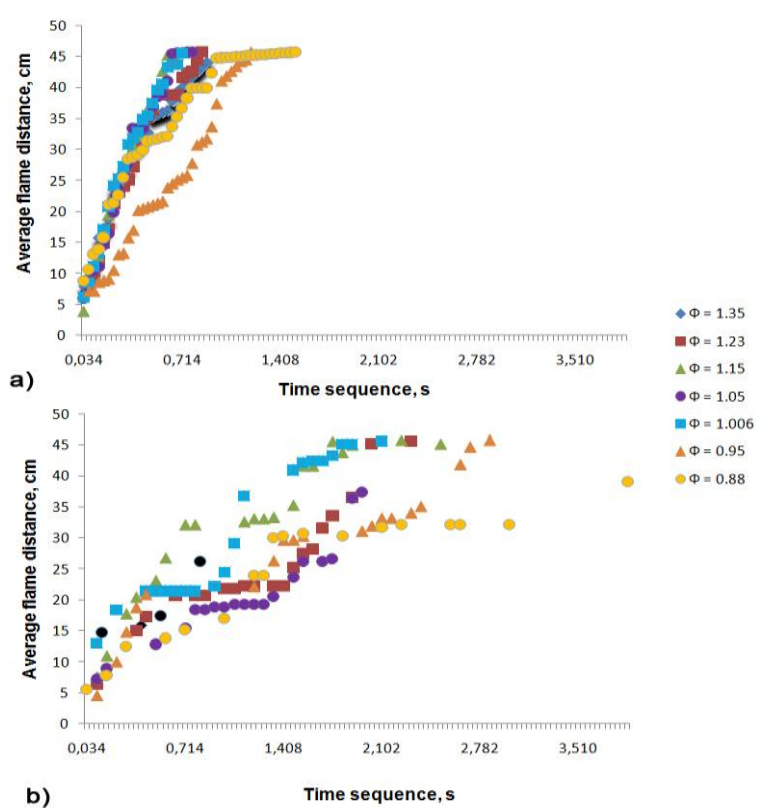

Figure 5. (a) Time variation of average flame distance ignited from the top and (b) time variation of average flame distance ignited from the bottom at various equivalence ratio

The delay is caused by the penetration of $\mathrm{CO}_{2}$ into the reaction zone which inhibits the flame propagation so that the flame propagation is slower than that at downward flame propagation.

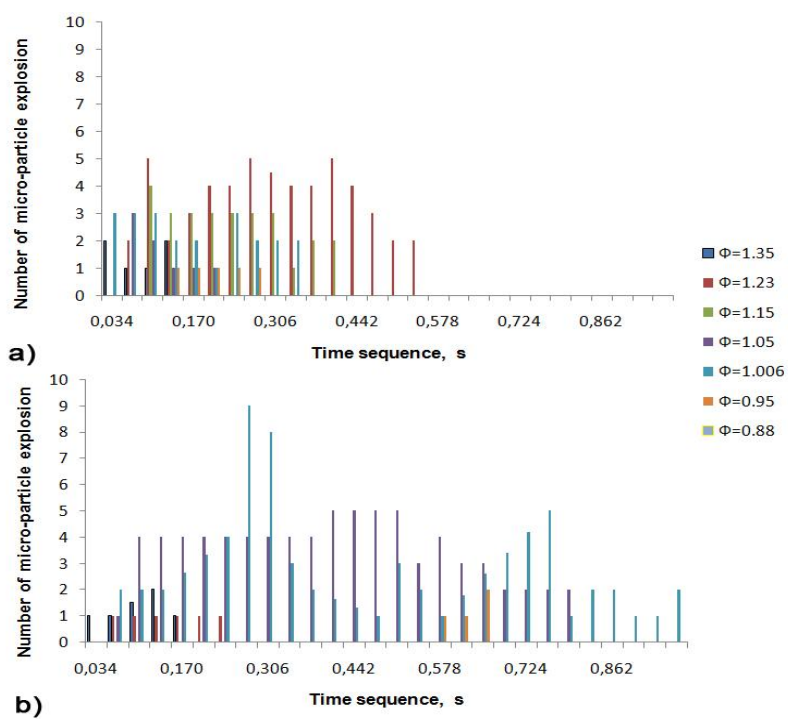

Figure 6 (a) Time variation of flame number of particle microexplosion ignited from the top and (b) time variation of flame number particle of micro-explosion ignited from the bottom at various equivalence ratio.

Figure 6a shows the number of micro-explosion in the flame ignited from top at various $\Phi$. It is seen that the number of micro-explosion is largest at $\Phi=1.23$. This is due to the greater fuel thermal conduction so the flame is thicker and the rate of reaction is slow. As a 
result, the flame propagation is slow. Consequently, glycerol has chance to absorb more water causing a large number of micro-explosion.

Figure 6.b. shows the number of micro-explosion at the flame propagation ignited from bottom. The number of micro-explosion is the largest at $\Phi=1.006$ shortly before propagation delay time from around 0.2 and 0.4 seconds (see Fig. 4b). The number of micro-explosion is much larger than that at flame propagation downward. This is due to the fact that during the delay glycerol has longer time to absorb water while the heat reaction is higher for faster flame propagation, causing a number of micro-explosion much higher than that in flame propagating downward in Figure 6a.

Figure $7 \mathrm{a}$ and $7 \mathrm{~b}$ shows the time variation of the average diameter of micro-explosion-to in the downward and upward flame propagation, respectively at various $\Phi$. The average diameter of micro-explosion is larger at the upward flame propagation. This is due to the fact that at upward flame propagation, there is a propagation delay time (see Fig. 5b) that gives more time for glycerol to absorb water vapor. The more water in glycerol produces larger micro-explosion.

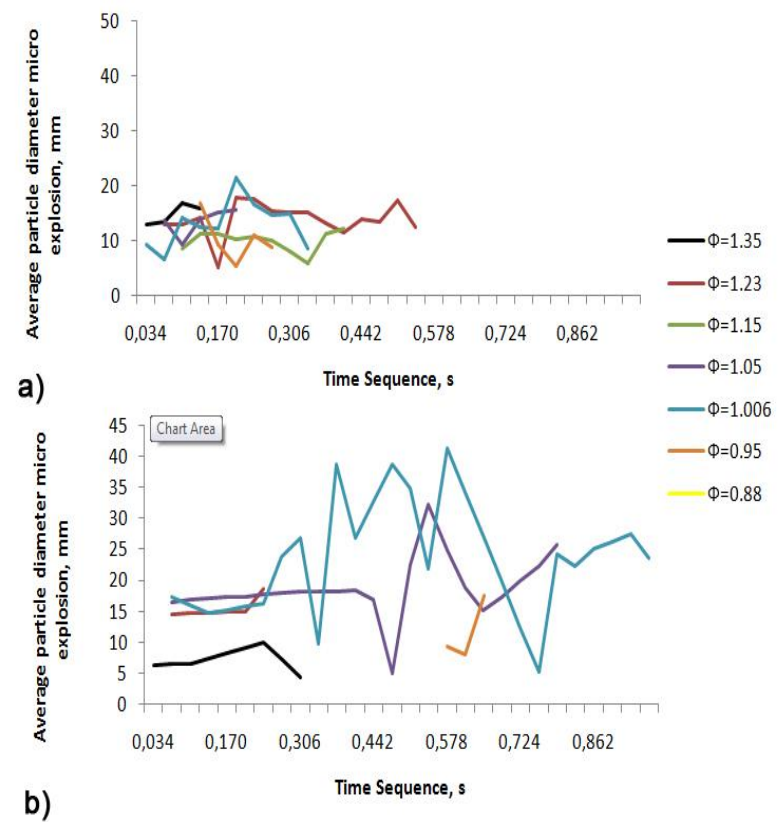

Figure 7a. Time variation of average flame particle diameter microexplosion ignited from the top and Figure 7.b. time variation of average flame particle diameter micro-explosion ignited from the bottom at various equivalence ratio

\section{Conclusion}

Result and understanding gained from this study can be summarized as follows:

- Water vapor from combustion products causes the hydrolysis reaction that produces glycerol and fatty acid. Fatty acid flame propagates first followed by that of glycerol.
- Glycerol tends to absorb water vapor producing micro-explosion.

- At equivalence ratio of 1.23 the fuel thermal conductivity is higher that makes the flame thicker and slows reaction rate so that glycerol has the opportunity to absorb water vapor causing more micro-explosions. At equivalence ratio of 1.006 the fuel thermal conductivity is smaller causing the flame is thinner and reaction rate is faster. Consequently, glycerol does not have enough time to absorb water vapor causing micro-explosions are few.

- For upward flame propagation at equivalence ratio of 1.23 , the fuel thermal conduction is greater resulting in the thicker flame and slower reaction rate. Moreover, $\mathrm{CO}_{2}$ penetrate into reaction zone that further reducing reaction rate. Though glycerol has a longer time to absorb water vapor, very low heat of reaction is not enough to produce microexplosions. At equivalence ratio of 1.006 the fuel thermal conductivity is smaller causing thinner flame and faster reaction rate. Though $\mathrm{CO}_{2}$ gas penetrates into reaction zone water vapor absorbed by glycerol produce a lot of micro-explosions due higher heat of reaction.

\section{Acknowledgment}

This work is supported by the Ministry of Education and Culture.

\section{References}

Abdulwahid, M., Khalid M. Saqr, Mohsin M. Sies and Haffis Ujir, (2009). Diffusive Thermal Instabilities of $\mathrm{C}_{4} \mathrm{H}_{10}-\mathrm{C}_{3} \mathrm{H}_{8} /$ Air Laminar Premixed Flames, diffusion-fundamentals.org 9( 8): 1-8

Agarwal D, \& Agarwal A.K., (2007). Performance and emission characteristics of jatropha oil (preheated and blends) in a direct injection compression ignition engine. Appl Therm Eng 27:231423.

Cornet, I., \& Nero, W.E., (1955). Emulsified Fuels in Compression Ignition Engines. Int. Eng. Chem. 47 (1955) 2133-2141.

Dee, V., Shaw B.D., 2004. Combustion of Propanol-Glycerol Mixture Droplets in Reduced Gravity. Int J Heat Mass Transfer. 47: 48574867.

Kang, S.H., Baek, S.W., Im, H. G., (2006). Effects of heat and momentum losses on the stability of premixed flames in a narrow channel. Combustion Theory and Modelling. Vol. 10, No. 4, August 2006, 659-681

Kratzeisen M., \& Müller J., (2010). Influence of Free Fatty Acid Content of Coconut Oil on Deposit and Performance of Plant Oil Pressure Stoves. Fuel. 89: 1583-1589.

Muniyappa, P.R., Brammer S.C., Noureddini H., (1996). Improved Conversion of Plant Oils and Animal Fats into Biodiesel and Coproduct. Bioresour Technol. 56:19-24.

Nam, H. and Alvarado, J.L., (2012), Microexplosion Detection in Hexadecane and Vegetable Oil Blends, Spring Technical Meeting of the Central States Section of the Combustion Institute April 2224,2012

Özkan, M, Ergenç A.T, Deniz O., (2005). Experimental Performance Analysis of Biodiesel, Traditional Diesel and Biodiesel with Glycerine. Turkish J Eng Env Sci. 29: 89-94.

Patel N., (2008). Virgin's Coconut-Powered 747 Completes First Fight. Downloaded from http://www. engadget.com /2008/02/25/ virgins-coconut-powered-747-completes-firstflight/>. 
Sahoo, PK and Das L.M., (2009). Combustion Analysis of Jatropha, Karanja and Polanga Based Biodiesel as Fuel in a Diesel Engine. Fuel. 88: 994-9.

Tanaka, H, Yamasaki H., Teraji S., Segawa D., Kadota T., (2005). Effect of Fuel Properties, Water Content and Surface Temperature on Micro-Explosion of Emulsion Droplet Burning on a Hot Surface. Trans Jpn Soc Mech Eng. 71(702):690-5 [in Japanese].

Turner, D.W., and Siegmund, C. W., Control of NOx from fuel oil combustion : water in oil emulsion, Presented at The Winter Symposium of the IEC Division of the American Chemical Society, 1973.

Wang, S.Y. Fu, L.J. Kung, C.K. Law, (2005), Combustion and microexplosion of collision-merged methanol/alkane droplets. Proceeding of the combustion Institute, Vol 30: 1965-1972
Wardana, I.N.G., (2010). Combustion Characteristics of Jatropha Oil Droplet at Various Oil Temperatures. Fuel. 89: 659-664,

Xu, G, Ikegami M., Honma S., Ikeda K., Ma X., Nagaishi H., (2003). Inverse Influence of Initial Diameter on Droplet Burning Rate in Hot and Cold Ambiences: a Thermal Action of Flame in Balance with Heat Loss. Int J Heat Mass Transfer. 46:1155-69.

Zhang, B.L., Williams F.A., (1998). Effects of the Lewis Number of Water Vapor on the Combustion and Extinction of Methanol Drops. Combust Flame. 112: 113-20. 